\title{
Comparison of Non-Linear and Linear Ho Models Applied for Copper lons Sorption on Geopolymer
}

\author{
Mario Nikola Mužek*, Sandra Svilović, Jelica Zelić
}

\begin{abstract}
The Ho pseudo-second-order model is the best fitting model in describing the sorption of copper ions on synthesized geopolymer for the selected experimental conditions (particle size $0.071-0.090 \mathrm{~mm}$ at agitation speed of $240 \mathrm{rpm}$ ). For that reason, a comparison of one non-linear and five linear forms of the Ho pseudo-second-order model was made in the present study in order to obtain the optimum sorption kinetic parameters using the experimental kinetic data obtained for the copper ions sorption process on the synthesized geopolymer. Taking all the results into consideration, the non-linear Ho model proved to be more consistent in describing the copper ions sorption on geopolymer for various initial concentrations of sorbent, as well as for various temperatures.
\end{abstract}

Keywords: copper; geopolymer; Ho pseudo-second-order model; linear regression; non-linear regression

\section{INTRODUCTION}

Sorption processes have been proved to be an effective method for the removal of various pollutants such as heavy metals and dyes from wastewaters. Therefore, the prediction of batch sorption kinetics is important for sorption processes design. It is important to determine how sorption rates depend on the initial concentrations or temperature of solution and how rates are affected by sorption capacity or by the character of sorbent in terms of kinetics. The solute uptake rate - which determines the residence time required for completion of the sorption reaction - may be analyzed and established from the kinetic analysis [1]. The nature of sorption process will depend on physical or chemical characteristics of the adsorbent systems and also on the system conditions [2].

The most commonly used kinetic models to explain the sorption processes are the pseudo-first-order and pseudosecond-order kinetic models [3, 4].

The Ho pseudo-second-order model [5] explains the kinetics of the most of sorption systems very well for the entire range of sorption period and it has been successfully applied to the adsorption of metal ions, dyes, herbicides, oils, and organic substances from aqueous solutions.

In previous work [6], the Ho pseudo-second-order model showed the best fitting with experimental data gained for the copper ions sorption on prepared geopolymer. For that reason, a comparison of one non-linear and five different linear forms of the Ho model was made in the present study in order to obtain the optimum sorption kinetic parameters using the experimental kinetic data obtained for the copper ions sorption on prepared geopolymer.

\section{MATERIALS AND METHODS}

The appropriate weight of $\mathrm{Cu}\left(\mathrm{NO}_{3}\right)_{2} \times 3 \mathrm{H}_{2} \mathrm{O}$ (Kemika) was dissolved in distilled water in order to prepare solutions containing copper ions. The procedure of geopolymer synthesis is given elsewhere as well as the FTIR, SEM/EDS, and XRD analysis of geopolymer synthesized $[6,7]$.
The suspensions were prepared by mixing $1.0 \mathrm{~g}$ of prepared geopolymer (particle size $0.071-0.090 \mathrm{~mm}$ ) with $0.2 \mathrm{~L}$ of copper (II) nitrate solution. The suspensions were mixed with a turbine impeller at $240 \mathrm{rpm}$ in the batch reactors. The influence of initial solute concentration (3.881, $5.915,7.780,9.898,11.763 \mathrm{mmol} \mathrm{L}^{-1}$ ) on sorption process at constant temperature $(298 \mathrm{~K})$ was investigated. The influence of various temperatures $(298 \mathrm{~K}, 308 \mathrm{~K}$, and $318 \mathrm{~K})$ on sorption process at constant initial solute concentration $\left(11.763 \mathrm{mmol} \mathrm{L}^{-1}\right)$ was also investigated.

Suspension samples were taken out from the batch reactors at specific times in order to determine the concentration of copper ions. Samples were centrifuged and filtered so the copper concentration could be determined by UV/Vis spectrophotometer (Perkin-Elmer Lambda EZ 201). Sampling was more frequent in the initial period of sorption process, however, as sorption slowed down, the frequency of sampling also decreased.

The copper amount sorbed on the prepared geopolymer at time $t, q_{\mathrm{t}}$, is determined by Eq. (1). It represents the difference between the concentration of copper ions present in the solution at the beginning of the experiment and in the sampling times.

$q_{t}=\frac{\left(c_{0}-c_{t}\right) V}{m}$

where $c_{0}$ is the initial concentration of copper in solution $\left(\mathrm{mmol} \mathrm{L}^{-1}\right), c_{t}$ is concentration of copper in solution at time $t$ $\left(\mathrm{mmol} \mathrm{L}^{-1}\right), V$ is the volume of solution (L), and $m$ is the mass of the synthesized geopolymer (g) [8].

The chi-square test $\chi^{2}$ was used to examine the fitting of different forms of the Ho pseudo-second-order model with experimental data. It is usually applied when the resulting correlation coefficients are very close and high [9]. The least square method was used to obtain parameters of the linear forms of the Ho pseudo-second-order model and non-linear regression analysis for the parameters of the non-linear form. 


\section{RESULTS AND DISCUSSION}

\subsection{Comparison of Non-Linear and Linear Forms of the Ho Model for Various Initial Concentrations}

The Ho model is presented as $[1,10]$ :

$$
\frac{\mathrm{d} q_{t}}{\mathrm{~d} t}=k_{2}\left(q_{\mathrm{e}}-q_{t}\right)^{2}
$$

where $q_{t}$ is amount of metal ions sorbed after time $t$ (mmol $\left.\mathrm{g}^{-1}\right), t$ is time ( $\left.\mathrm{min}\right), q_{\mathrm{e}}$ is equilibrium (maximum) amount of copper ions sorbed $\left(\mathrm{mmol} \mathrm{g}^{-1}\right)$, and $k_{2}$ is the rate constant of the model used $\left(\mathrm{g} \mathrm{mmol}^{-1} \mathrm{~min}^{-1}\right)$.

In the present study the experimental kinetic data for the sorption of copper ions onto synthesized geopolymer were fitted to the five different linearized forms of Ho pseudosecond order model, as well as its non-linear form. Both, nonlinear and linear forms of Ho model were given in Tab. 1. The Ho pseudo-second-order kinetic constant $k_{2}\left(\mathrm{~g} \mathrm{mmol}^{-1}\right.$ $\min ^{-1}$ ) and maximum amount of copper ions retained on geopolymer can be calculated from the plots given in Tab. 1.

The Ho pseudo-second-order kinetic parameters gained for various concentrations are calculated and presented in Tab. 2. According to the values obtained it could be noticed that values for kinetic parameters are different among the linear and non-linear forms. The best values of $\chi^{2}-$ test among linear forms of Ho pseudo-second-order model were gained for linear type 2 for all the concentrations analyzed (Fig. 1).

\begin{tabular}{|c|c|c|c|}
\hline & Equation & Plot & Parameters \\
\hline Non-linear form & $q_{t}=\frac{t}{\frac{1}{k_{2} q_{\mathrm{e}}^{2}}+\frac{t}{q_{\mathrm{e}}}}$ & $q_{t} \mathrm{vs} t$ & $q_{\mathrm{e}}, k_{2}$ \\
\hline Linear type 1 & $\frac{1}{q_{t}}=\frac{1}{k_{2} q_{\mathrm{e}}^{2}}+\frac{1}{q_{\mathrm{e}}} t$ & $\frac{1}{q_{t}} \mathrm{vs} t$ & $q_{\mathrm{e}}=\frac{1}{\text { slope }}, k_{2}=\frac{\text { slope }^{2}}{\text { intercept }}$ \\
\hline Linear type 2 & $\frac{1}{q_{t}}=\left(\frac{1}{k_{2} q_{\mathrm{e}}^{2}}\right) \frac{1}{t}+\frac{1}{q_{\mathrm{e}}}$ & $\frac{1}{q_{t}}$ vs $\frac{1}{t}$ & $q_{\mathrm{e}}=\frac{1}{\text { intercept }}, k_{2}=\frac{\text { intercept }^{2}}{\text { slope }}$ \\
\hline Linear type 3 & $\frac{1}{t}=\frac{k_{2} q_{\mathrm{e}}^{2}}{q_{t}}-\frac{k_{2} q_{\mathrm{e}}^{2}}{q_{\mathrm{e}}}$ & $\frac{1}{t}$ vs $\frac{1}{q_{t}}$ & $q_{\mathrm{e}}=\frac{- \text { slope }}{\text { intercept }}, k_{2}=\frac{\text { intercept }^{2}}{\text { slope }}$ \\
\hline Linear type 4 & $\frac{q_{t}}{t}=k_{2} q_{\mathrm{e}}^{2}-k_{2} q_{\mathrm{e}} q_{t}$ & $\frac{q_{t}}{t}$ vs $q_{t}$ & $q_{\mathrm{e}}=\frac{\text {-intercept }}{\text { slope }}, k_{2}=\frac{\text { slope }^{2}}{\text { intercept }}$ \\
\hline Linear type 5 & $q_{t}=q_{\mathrm{e}}-\left(\frac{1}{k_{2} q_{\mathrm{e}}}\right) \frac{q_{t}}{t}$ & $q_{t}$ vs $\frac{q_{t}}{t}$ & $q_{\mathrm{e}}=$ intercept,$k_{2}=\frac{-1}{\text { slope } \times \text { intercep }}$ \\
\hline
\end{tabular}

Table 2 The calculated parameters of the Ho pseudo-second-order model for copper ions sorbed on prepared geopolymer by linear and non-linear regression analysis for various initial concentrations

\begin{tabular}{|c|c|c|c|c|c|c|}
\hline & Parameter & $3.881 \mathrm{mmol} \mathrm{L}^{-1}$ & $5.915 \mathrm{mmol} \mathrm{L}^{-1}$ & $7.780 \mathrm{mmol} \mathrm{L}^{-1}$ & $9.898 \mathrm{mmol} \mathrm{L}^{-1}$ & $11.763 \mathrm{mmol} \mathrm{L}^{-1}$ \\
\hline & $q_{\text {eexp. }}$ & 0.775 & 1.058 & 1.099 & 1.114 & 1.136 \\
\hline \multirow{3}{*}{ Linear type 1} & $q_{\mathrm{e}}^{*}$ & 0.770 & 1.063 & 1.108 & 1.126 & 1.153 \\
\hline & $k_{2}{ }^{\Delta}$ & 25.7345 & 0.999 & 0.719 & 0.691 & 0.567 \\
\hline & $\chi^{2}$ & 0.013 & 0.174 & 0.294 & 0.233 & 0.376 \\
\hline \multirow{3}{*}{ Linear type 2} & $q_{\mathrm{e}}$ & 0.778 & 1.017 & 1.033 & 1.045 & 1.047 \\
\hline & $k_{2}$ & 9.136 & 2.115 & 1.807 & 1.568 & 1.455 \\
\hline & $\chi^{2}$ & $1.760 \times 10^{-3}$ & 0.014 & 0.032 & 0.044 & 0.070 \\
\hline \multirow{3}{*}{ Linear type 3} & $q_{\mathrm{e}}$ & 0.780 & 1.026 & 1.051 & 1.069 & 1.082 \\
\hline & $k_{2}$ & 8.408 & 1.920 & 1.521 & 1.292 & 1.114 \\
\hline & $\chi^{2}$ & 0.450 & 0.564 & 0.160 & 0.165 & 0.413 \\
\hline \multirow{3}{*}{ Linear type 4} & $q_{\mathrm{e}}$ & 0.780 & 1.033 & 1.064 & 1.085 & 1.105 \\
\hline & $k_{2}$ & 8.542 & 1.782 & 1.357 & 1.138 & 0.952 \\
\hline & $\chi^{2}$ & 0.341 & $9.066 \times 10^{-3}$ & 0.185 & 0.132 & 0.072 \\
\hline \multirow{3}{*}{ Linear type 5} & $q_{\mathrm{e}}$ & 0.778 & 1.023 & 1.044 & 1.060 & 1.067 \\
\hline & $k_{2}$ & 9.430 & 1.992 & 1.651 & 1.412 & 1.279 \\
\hline & $\chi^{2}$ & $1.069 \times 10^{-3}$ & 0.014 & 0.035 & 0.048 & 0.077 \\
\hline \multirow{3}{*}{ Non-linear type } & $q_{\mathrm{e}}$ & 0.783 & 1.031 & 1.061 & 1.084 & 1.100 \\
\hline & $k_{2}$ & 9.544 & 1.776 & 1.358 & 1.111 & 0.933 \\
\hline & $\chi^{2}$ & $9.624 \times 10^{-4}$ & 0.010 & 0.025 & 0.033 & 0.054 \\
\hline
\end{tabular}

${ }^{*} q_{\mathrm{e}}(\mathrm{mmol} \mathrm{g})^{-1} k_{2}\left(\mathrm{~g} \mathrm{mmol}^{-1} \min ^{-1}\right)$

Nevertheless, values gained for maximum amount of copper ions sorbed on prepared geopolymer, $q_{\mathrm{e}}$, for linear type 2 are not in a good agreement with experimentally obtained values except for the initial concentration of 3.881 mmol L ${ }^{-1}$. 
All the linear and non-linear types showed good agreement with experimentally obtained values for maximum amount of copper ions sorbed on geopolymer for the lowest initial concentration of heavy metal $(3.881 \mathrm{mmol}$ $\left.\mathrm{L}^{-1}\right)$. Values gained for maximum amount of copper ions sorbed on prepared geopolymer, $q_{\mathrm{e}}$, for linear type 1 are in better agreement with experimentally obtained values apart from values gained for other linear forms but calculated values of $\chi^{2}$ - test for linear type 1 are also among the highest ones.
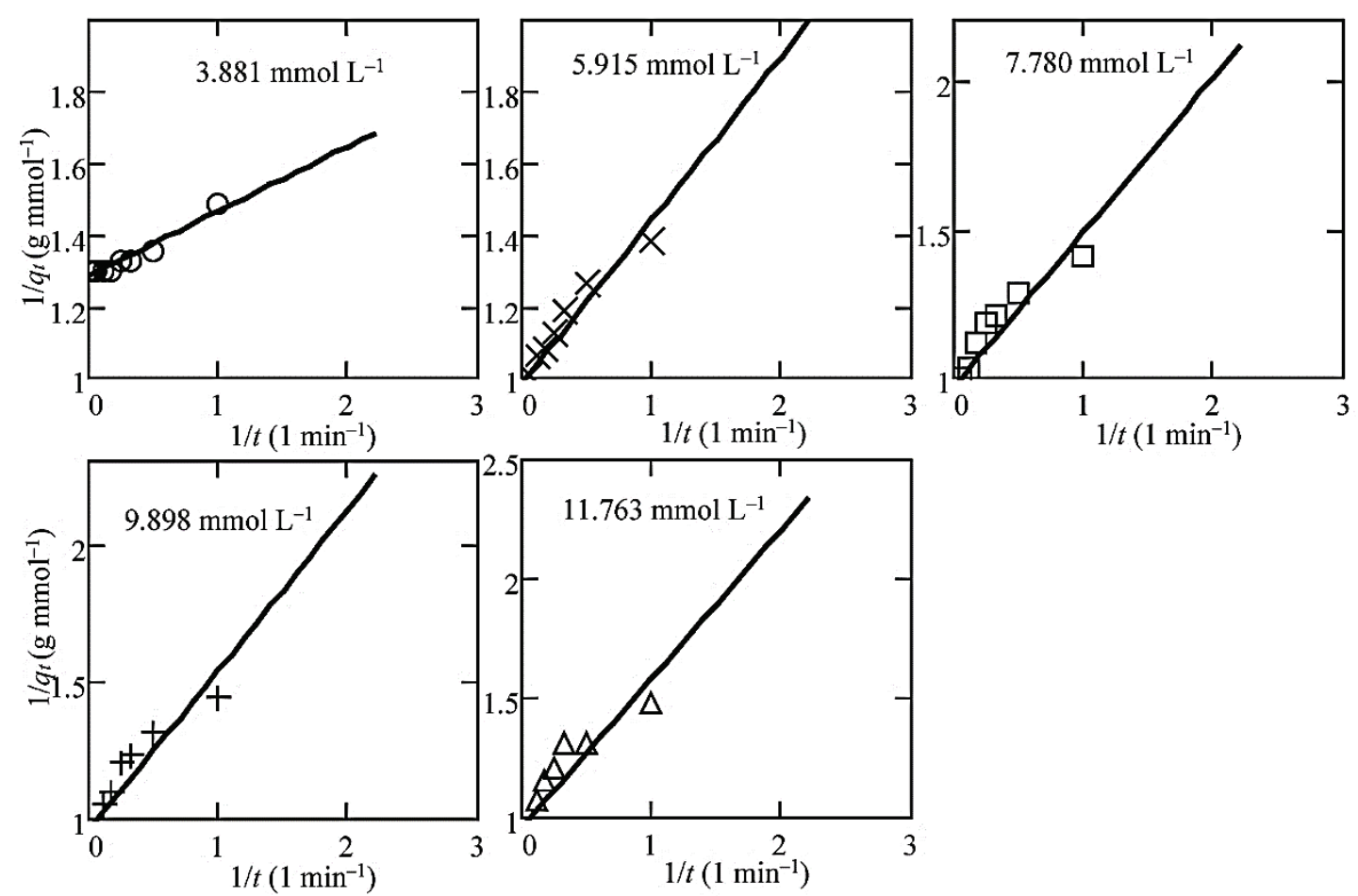

Figure 1 Linear type 2 of Ho model for the sorption of copper ions on prepared geopolymer for various initial concentrations

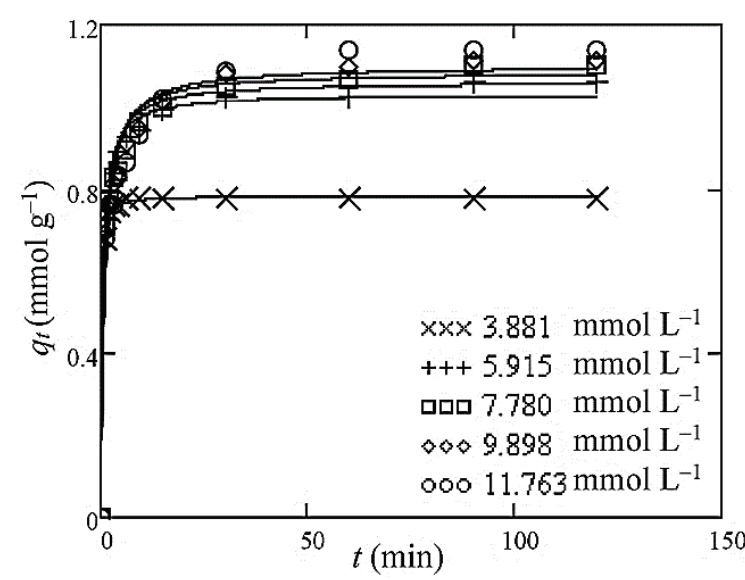

Figure 2 Non-linear Ho model for the sorption of copper ions on prepared geopolymer for various initial concentrations

Nevertheless, non-linear form is better for describing a copper ions sorption process on prepared geopolymer (Fig. 2 ); values of $\chi^{2}-$ test are lower than ones gained in linear forms of Ho pseudo-second-order model. The values of maximum amount of copper ions retained on geopolymer are also in good agreement with those gained experimentally (Tab. 2). For all the reasons mentioned, the non-linear form is more suitable and precise in describing the sorption process of copper ions on prepared geopolymer for various concentrations.

\subsection{Comparison of Non-Linear and Linear Forms of the Ho Model for Various Temperatures}

The best values of $\chi^{2}$ - test among linear forms of Ho pseudo-second-order model were gained for linear type 2, Fig. 3, but the values obtained for maximum amount of copper ions sorbed on prepared geopolymer, $q_{\mathrm{e}}$, are not, again, in a good agreement with experimentally obtained values. Linear type 1 showed best agreement for the values of maximum amount of copper ions sorbed on prepared geopolymer, $q_{\mathrm{e}}$, but values obtained for $\chi^{2}-$ test are among the highest ones for linear types.

Non-linear form once again confirmed to be good for calculation of kinetic parameters of sorption process tested. Values of $\chi^{2}$ - test for non-linear form are lower than ones gained for linear forms of Ho pseudo-second-order model. The values of maximum amount of copper ions retained on geopolymer are in a good agreement with those gained experimentally (Tab. 3 ).

The Ho pseudo-second-order kinetic parameters gained for various temperatures are calculated and presented in Tab. 3. 

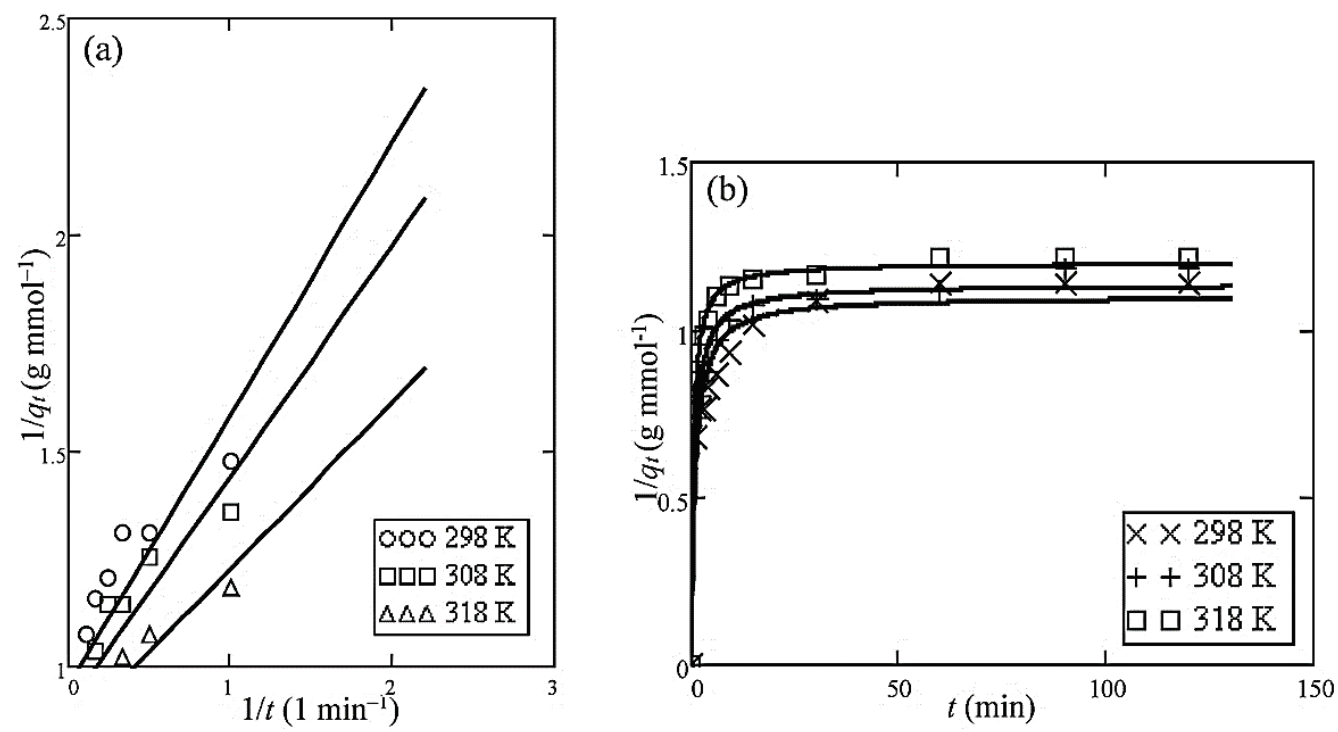

Figure $3 \mathrm{Ho}$ model for the sorption of copper ions on prepared geopolymer for various temperatures: (a) linear type 2, (b) non-linear form

Table 3 The calculated parameters of the Ho pseudo-second-order model for copper ions sorbed on geopolymer by linear and non-linear regression analysis for various temperatures

\begin{tabular}{|c|c|c|c|c|}
\hline \multirow{4}{*}{ Linear type 1 } & Parameter & $298 \mathrm{~K}$ & $308 \mathrm{~K}$ & $318 \mathrm{~K}$ \\
\cline { 2 - 5 } & $q_{\text {eexp. }}$ & 1.136 & 1.183 & 1.217 \\
\cline { 2 - 5 } & $q_{\mathrm{e}}{ }^{3}$ & 1.153 & 1.191 & 1.225 \\
\cline { 2 - 5 } & $k_{2}{ }^{{ }^{2}}$ & 0.567 & 0.568 & 1.067 \\
\hline \multirow{3}{*}{ Linear type 2 } & $\chi^{2}$ & 0.376 & 0.466 & 0.071 \\
\cline { 2 - 5 } & $q_{\mathrm{e}}$ & 1.047 & 1.101 & 1.185 \\
\cline { 2 - 5 } & $k_{2}$ & 1.455 & 1.550 & 1.856 \\
\hline \multirow{3}{*}{ Linear type 3 } & $\chi_{\mathrm{e}}$ & 0.070 & 0.035 & $9.072 \times 10^{-3}$ \\
\cline { 2 - 5 } & $k_{2}$ & 1.082 & 1.123 & 1.194 \\
\cline { 2 - 5 } & $\chi^{2}$ & 0.413 & 1.297 & 1.714 \\
\hline \multirow{3}{*}{ Linear type 4 } & $q_{\mathrm{e}}$ & 1.105 & 1.138 & 0.107 \\
\cline { 2 - 5 } & $k_{2}$ & 0.952 & 1.157 & 1.200 \\
\cline { 2 - 5 } & $\chi^{2}$ & 0.072 & $8.179 \times 10^{-3}$ & 0.107 \\
\cline { 2 - 5 } & $q_{\mathrm{e}}$ & 1.067 & 1.114 & 1.191 \\
\cline { 2 - 5 } & $k_{2}$ & 1.279 & 1.413 & 1.763 \\
\cline { 2 - 5 } & $\chi^{2}$ & 0.077 & 0.044 & 0.013 \\
\cline { 2 - 5 } & $q_{\mathrm{e}}$ & 1.100 & 1.135 & 1.200 \\
\cline { 2 - 5 } & $k_{2}$ & 0.933 & 1.146 & 1.600 \\
\cline { 2 - 5 } & $\chi^{2}$ & 0.054 & 0.029 & $8.921 \times 10^{-3}$ \\
\hline
\end{tabular}

$* q_{\mathrm{e}}\left(\mathrm{mmol} \cdot \mathrm{g}^{-1}\right)^{\Delta} k_{2}\left(\mathrm{~g} \cdot \mathrm{mmol}^{-1} \cdot \mathrm{min}^{-1}\right)$

\section{CONCLUSIONS}

Linear forms are more or less successful in describing the sorption process of copper ions on geopolymers. Linear type 2 of Ho pseudo-second-order is the most suitable taking the values of $\chi^{2}$ - test into account. Nevertheless, $q_{\mathrm{e}}$ values are not in a good agreement with experimentally obtained values.

Taking all the results into consideration, the non-linear Ho pseudo-second-order kinetic model form is much better and consistent for fitting the copper ions sorption process on synthesized geopolymer for the selected experiment conditions for various initial concentrations of sorbent, as well as for various temperatures.

\section{REFERENCES}

[1] Ho, Y. S. \& McKay, G. (1998). The kinetics of sorption of basic dyes from aqueous solution by sphagnum moss peat. The Canadian Journal of Chemical Engineering, 76(4), 822-827. https://doi.org/10.1002/cjce.5450760419

[2] Kumar, K. V. (2006). Linear and non-linear regression analysis for the sorption kinetics of methylene blue onto activated carbon. Journal of Hazardous Materials, 137(3), 1538-1544. https://doi.org/10.1016/j.jhazmat.2006.04.036

[3] Ho, Y. S. \& McKay, G. (1998). A two-stage batch sorption optimized design for dye removal to minimize contact time. Institution of Chemical Engineers Trans IChemE, 76(B), 313318. https://doi.org/10.1205/095758298529678

[4] Kumar, K. V., Ramamurthi, V., \& Sivanesan, S. (2005). Modeling the mechanism involved during the sorption of methylene blue onto fly ash. Journal of Colloid and Interface Science, 284(1), 14-21. https://doi.org/10.1016/j.jcis.2004.09.063

[5] Ho, Y. S. (2006). Review of second-order models for adsorption systems. Journal of Hazardous Materials, 136(3), 681-689. https://doi.org/10.1016/j.jhazmat.2005.12.043

[6] Mužek, M. N., Svilović, S., \& Zelić, J. (2014). Fly ash-based geopolymeric adsorbent for copper ion removal from wastewater. Desalination and Water Treatment, 52(13-15), 2519-2526. https://doi.org/10.1080/19443994.2013.792015

[7] Mužek, M. N., Svilović, S., Ugrina, M., \& Zelić, J. (2016). Removal of copper and cobalt ions by fly ash-based geopolymer from solutions-equilibrium study. Desalination and Water Treatment, 57(23), 10689-10699. https://doi.org/10.1080/19443994.2015.1040077

[8] Svilović, S., Rušić, D., \& Žanetić, R. (2008). Thermodynamics and adsorption isotherms of copper ions removal from solutions using synthetic zeolite X. Chemical and Biochemical Engineering Quarterly, 22(3), 299-305.

[9] Arshadi, M., Amiri, M. J., \& Mousavi, S. (2014). Kinetic, equilibrium and thermodynamic investigations of $\mathrm{Ni}(\mathrm{II})$, $\mathrm{Cd}(\mathrm{II}), \mathrm{Cu}(\mathrm{II})$ and $\mathrm{Co}(\mathrm{II})$ adsorption on barley straw ash. Water Resources and Industry, 6, 1-17. https://doi.org/10.1016/j.wri.2014.06.001

[10] Ho, Y. S. (2003). Removal of copper ions from aqueous solution by tree fern. Water Research, 37(10), 2323-2330. https://doi.org/10.1016/S0043-1354(03)00002-2 
Authors' contacts:

Mario Nikola Mužek, Assistant Professor

(Corresponding author)

Faculty of Chemistry and Technology,

Department of Inorganic Technology,

Ruđera Boškovića 35, 21000 Split, Croatia

muky@ktf-split.hr

Sandra Svilović, Associate Professor

Faculty of Chemistry and Technology,

Department of Chemical Engineering,

Ruđera Boškovića 35, 21000 Split, Croatia

sandra@ktf-split.hr

Jelica Zelić, Full Professor

Faculty of Chemistry and Technology,

Department of Inorganic Technology,

Ruđera Boškovića 35, 21000 Split, Croatia

zelic@ktf-split.hr 